\title{
Preliminary Experimental Research on MHD Assisted Mixing and Combustion
}

\author{
Ling $\mathrm{GAO}^{\mathrm{a}}$, Bai-Ling ZHANG, Yi-Wen LI ${ }^{\mathrm{b}, *}$, Peng-Yu YANG, Hao FAN, \\ Cheng-Duo DUAN, Yu-Tian WANG
}

Plasma-Dynamic Laboratory, Air Force Engineering University, Xi'an, Shaanxi 710038, China

akgdlinggao@126.com, 'lee_yiwen@163.com

${ }^{*}$ Corresponding author

Keywords: MHD, Assisted Mixing, Combustion Chamber, Emission Reduction, Plasma.

\begin{abstract}
In order to effectively control the emissions, a MHD assisted mixing technique is presented and a MHD assisted mixing experiment system is developed. The experiment shows that with the help of MHD assisted mixing technique, the contacting surface between fuel and oxidant increase, thus make the combustion more sufficient, and improve the combustion efficiency with emission reduction.
\end{abstract}

\section{Introduction}

The process of the mixture of gaseous fuel and oxidant is one of the fundamental subjects of combustion and propulsion research [1]. It is obvious that the better (faster) mixing is the higher combustion efficiency can be reached in similar conditions [2]. However, the mixing process is generally speaking very slow process in scale of available mixing time, which is limited by residence time in combustion zone [3]. To enhance the other large scale, mechanism of mixing is introduced. The main idea is to increase the contacting surface between fuel and oxidant [4]. Because the electromotive body force $\mathrm{J} \times \mathrm{B}$ can increase the contact surfacein airflow, a MHD assisted mixing technique is developed [5].

\section{Experiments}

\section{Experimental Setup}

Experimental facility designed to study MHD assisted mixing and combustion is shown in Fig.1. The base element of the facility is the vacuum chamber in form of steel cylinder of $0.8 \mathrm{~m}^{3}$. Vacuum gauge is used to test the pressure of the vacuum chamber.

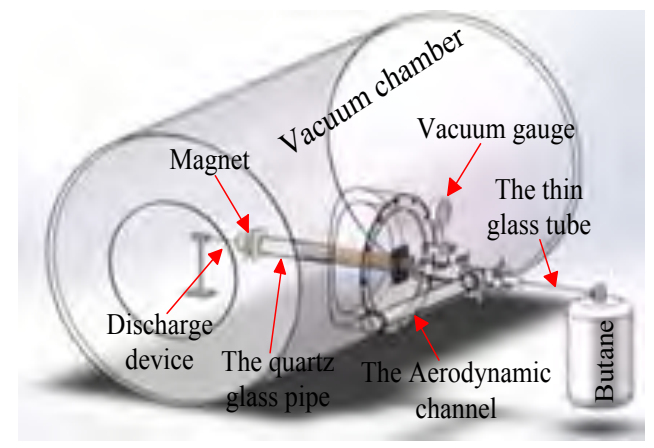

Fig. 1 The Test Section of the Experimental Setup

The Aerodynamic channel is controlled by vacuum valve, which consists of $50 \mathrm{~cm}$ length and $44 \mathrm{~mm}$ diameter steel duct and quartz glass pipe with the same parameter. Previously calibrated measuring washers were used for the flow velocities measurement. Fuel injection is performed along the main air stream through the injection system which is represented by the $4 \mathrm{~mm}$ diameter thin glass tube mounted on the aerodynamic channel axis (Fig.2). 
The electrical discharge is initiated between the annular electrode building-in quartz glass pipe and the wire electrode fixed on the thin glass tube axis. The width of annular electrode is $10 \mathrm{~mm}$, thediameter of wire electrode is $2 \mathrm{~mm}$. Brass is used as electrode material. QPC-5A DC power supply with $3.5 \mathrm{kV}$ voltage and $1 \mathrm{~A}$ current in maximum is used for direct current discharge igniting with cascading a $2.4 \mathrm{k} \Omega$ resistance. Longitudinal magnetic field is generated in the system by the electric solenoid made of $0.8 \mathrm{~mm}$ diameter copper wire and positioned coaxially with the quartz glass pipe. The electric solenoid is powered by storage battery. A single lens reflection is used for discharge visualization.

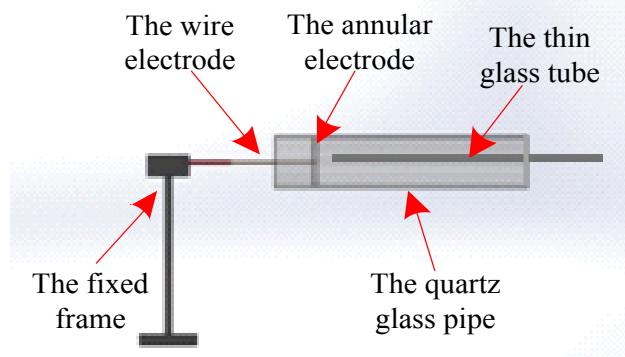

Fig. 2 The Scheme of the Facility

\section{Experimental Scheme}

The scheme of the experiment is shown in Fig.3. The main stream (air) 1 comes into the test section from left to right. The fuel (butane) 2 is injected also from left to right. The discharge 6 is created between the annular 5 and wire 4 electrodes. The discharge current aligns with the external magnetic field 3 and as the result the electromotive body force causes the electrical discharge movement and deformation across the air-butane contact surface providing conditions for better mixing.

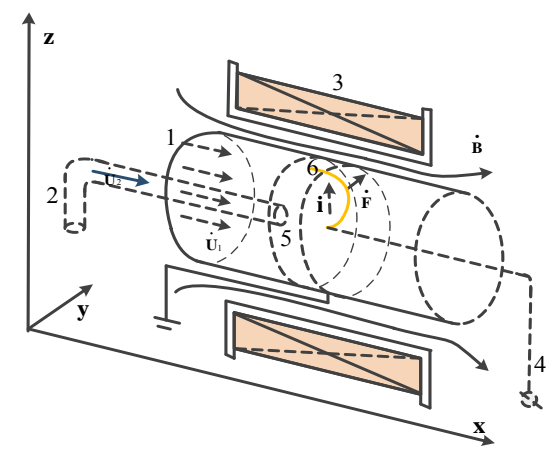

Fig. 3 Schematic of the Experiment on MHD assisted Mixing and Combustion

\section{Experimental Results}

Experimental studies in different typical working conditions are carried out on this system to display the influences that MHD shadow on mixing and combustion. The experimental results are presented below.

\section{The Discharge Evolution in Different Magnetic Field for Non-flow Conditions}

Photos in Fig.4 demonstrate the discharge evolution in $26 \mathrm{mT}$ magnetic field for non-flow conditions

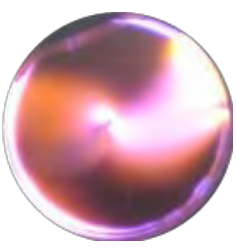

$0.8 s$

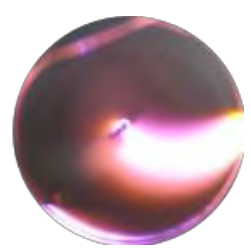

$1.3 \mathrm{~s}$

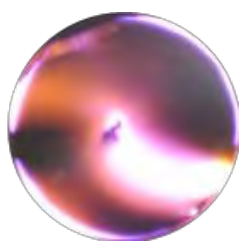

$1.7 \mathrm{~s}$

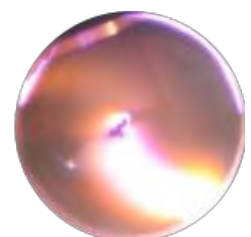

$2.5 s$

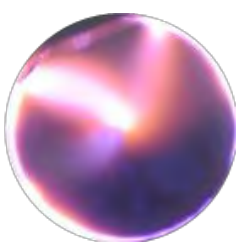

$3.4 s$

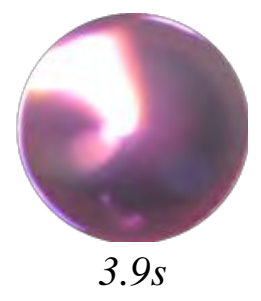

Fig. 4 The Discharge Evolution in $26 \mathrm{mT}$ Magnetic Field for Non-flow Conditions $(\mathrm{P}=1.5 \mathrm{kPa}, \mathrm{U}=1.5 \mathrm{kV})$ 
Static pressure in the test section was $1.5 \mathrm{kPa}$. Correspondingly, the voltage was $1.5 \mathrm{kV}$ in magnetic field. Its current direction is from the wire electrode to the annular one. The magnetic fieldis applied beyond the figure plain, so the electromotive body force acts in clockwise direction. It is clearly seen from the photos the spiral shape and the rotation of the discharge caused by its current interaction with the transversal external magnetic field and by the reconnection effects. The important detail of the observed discharge is the higher curvature and the rotational speed ofthe arc channel near the central electrode.

The discharge in $8 \mathrm{mT}$ magnetic fields without airflow is shown in Fig.5. As distinct from previous case there is intensive discharge rotation at the annular electrode here.

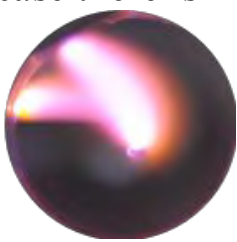

$0.6 \mathrm{~s}$

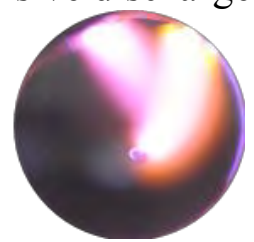

$1.4 \mathrm{~s}$

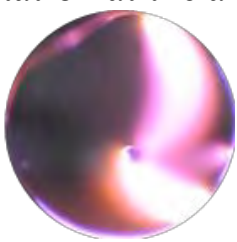

$1.9 \mathrm{~s}$

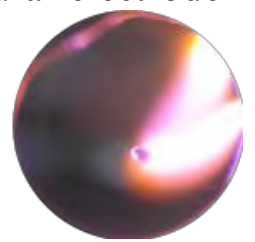

$2.6 \mathrm{~s}$

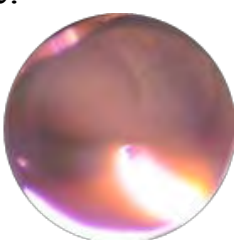

$3.2 \mathrm{~s}$

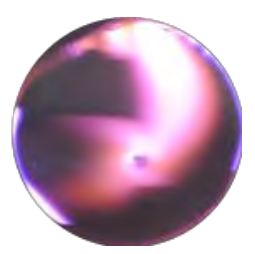

$3.9 \mathrm{~s}$

Fig. 5 The Discharge Evolution in $8 \mathrm{mT}$ Magnetic Field for Non-flow Conditions $(\mathrm{P}=1.5 \mathrm{kPa}, \mathrm{U}=1.5 \mathrm{kV})$

The discharge in $45 \mathrm{mT}$ magnetic fields without airflow is shown in Fig.6. As distinct from previous case there is intensive discharge rotation at the annular electrode here, but the curvature of discharge section is slight.

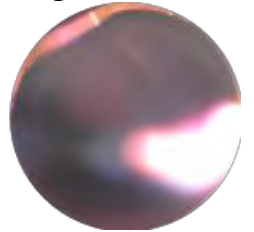

$0.5 \mathrm{~s}$

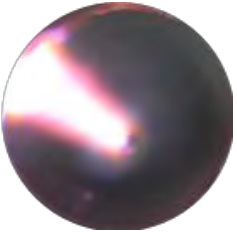

$0.9 \mathrm{~s}$

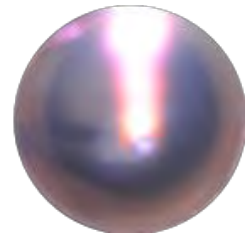

$1.3 \mathrm{~s}$

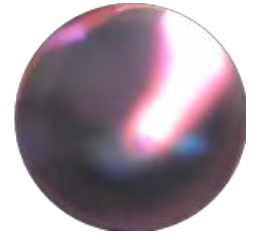

$1.8 \mathrm{~s}$

Fig. 6 The Discharge Evolution in $45 \mathrm{mT}$ Magnetic Field for Non-flow Conditions $(\mathrm{P}=1.5 \mathrm{kPa}, \mathrm{U}=1.5 \mathrm{kV})$

The fig.4-6 shows that the charged particles diffuse by spiral movement because of Lorentz force, this movement reduces the diffusion rate and increases the concentration of electrically charged particles in the discharge section, and the spiral movement also stop the local concentration of charged particles, such kind of behavior prevent discharge from shifting into unstable discharge in the high electron number density. This phenomenon becomes more obvious when magnetic flux density increase.

Photos in Fig.7 demonstrate the discharge evolution in $26 \mathrm{mT}$ magnetic field and static pressure was $2 \mathrm{kPa}$ for non-flow conditions, as distinct from previous case there is intensive curvature and rotational speed at the annular electrode here.

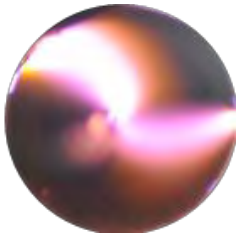

$0.5 \mathrm{~s}$

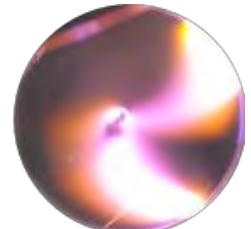

$1.2 \mathrm{~s}$

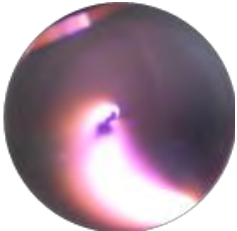

$1.6 \mathrm{~s}$

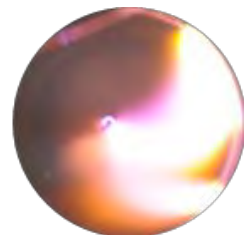

$2.3 \mathrm{~s}$

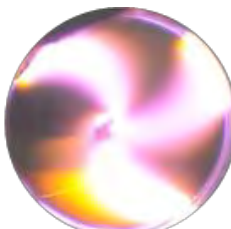

$2.9 \mathrm{~s}$

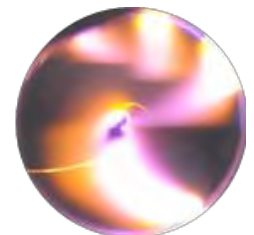

$3.3 \mathrm{~s}$

Fig. 7 The Discharge Evolution in 26mT Magnetic Field for Non-flow Conditions ( $\mathrm{P}=2 \mathrm{kPa}, \mathrm{U}=1.5 \mathrm{k} \mathrm{V})$

Photos in fig. 4 and fig. 7 show that with the increase of the pressure, plasma generating area becomes more diffusing due to the increase of particle collision rate resulting from the increase of pressure.

\section{The Discharge Evolution in Different Magnetic Field for Flow Conditions}

Photos in Fig. 8 represent the discharge evolution in $38 \mathrm{mT}$ magnetic field with airflow of $10 \mathrm{~m} / \mathrm{s}$ velocity directed opposite the external magnetic field induction vector. Static pressure in the test 
section was $1.5 \mathrm{kPa}$. With the help of flow, the section of discharge near the annular electrode become wide, and the discharge position only occur in a particular area. Moreover, it is clearly seen from the photos the spiral shape and the rotation of the discharge have disappeared.

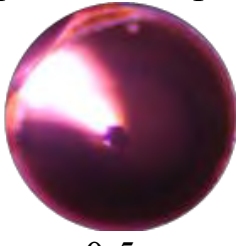

$0.5 \mathrm{~s}$

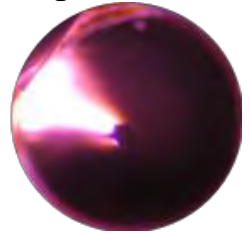

$1.3 \mathrm{~s}$

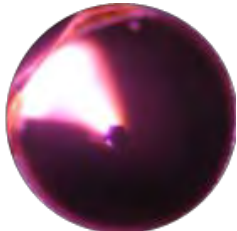

$1.7 \mathrm{~s}$

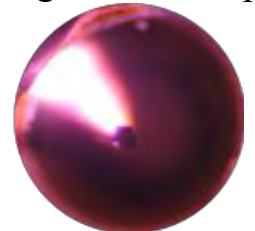

$2.1 \mathrm{~s}$

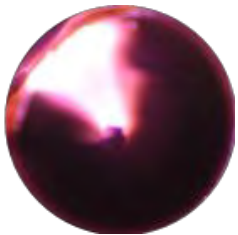

$2.7 \mathrm{~s}$

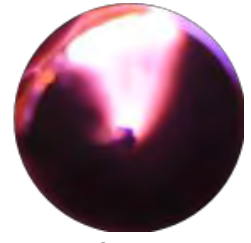

$3.5 \mathrm{~s}$

Fig. 8 The Discharge Evolution in $38 \mathrm{mT}$ Magnetic Field with Airflow $10 \mathrm{~m} / \mathrm{s}$ Velocity $(\mathrm{P}=1.5 \mathrm{kPa}$, $\mathrm{U}=1.5 \mathrm{kV}$ )

To resolve the discharge current evolution the velocity of airflow was increased. The appropriate discharge evolution in $38 \mathrm{mT}$ magnetic field with airflow $20 \mathrm{~m} / \mathrm{s}$ velocity is shown in Fig.9. The photos show that the discharge in the different section, and the section become narrow, but they are more stable.
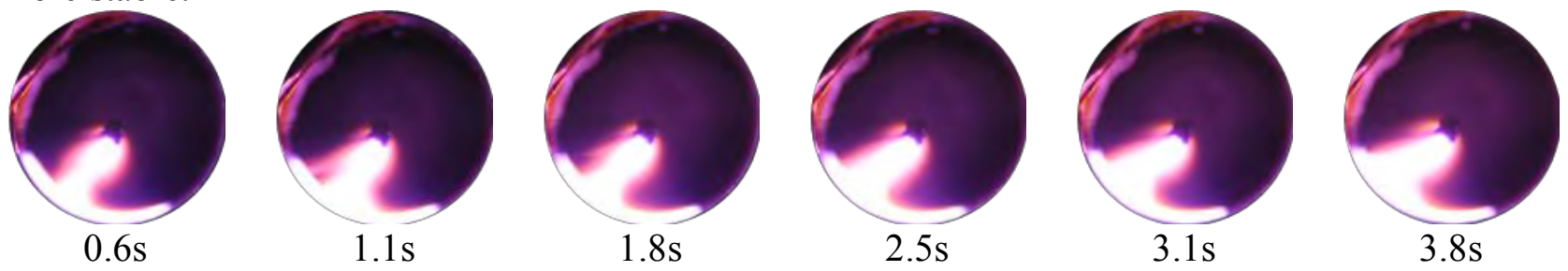

Fig. 9 The Discharge Evolution in $38 \mathrm{mT}$ Magnetic Field with Airflow $20 \mathrm{~m} / \mathrm{s}$ Velocity $(\mathrm{P}=1.5 \mathrm{kPa}$, $\mathrm{U}=1.5 \mathrm{kV}$ )

Fig.10. shows the evolution of discharge current in $38 \mathrm{mT}$ magnetic field with airflow $40 \mathrm{~m} / \mathrm{s}$ velocity. The section of discharge also different compare with velocity of $10 \mathrm{~m} / \mathrm{s}$ and $20 \mathrm{~m} / \mathrm{s}$. the section of discharge become not so steady, with some trembles.

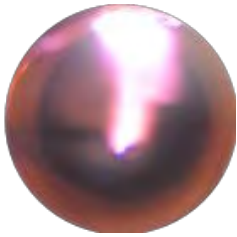

$0.5 \mathrm{~s}$

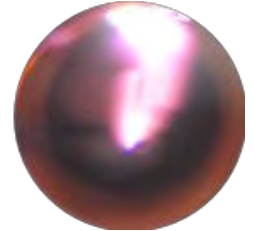

$0.9 \mathrm{~s}$

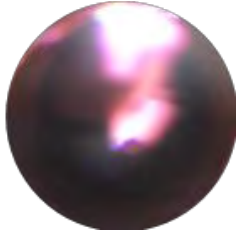

$1.4 \mathrm{~s}$

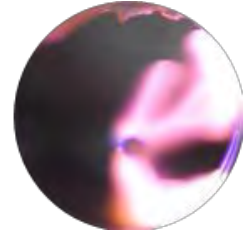

$1.8 \mathrm{~s}$

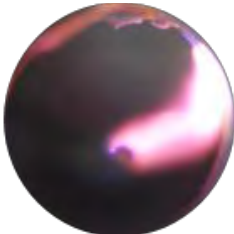

$2.1 \mathrm{~s}$

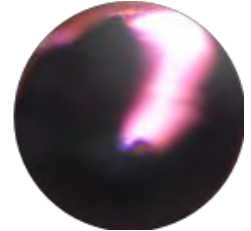

$2.7 \mathrm{~s}$

Fig. 10 The Discharge Evolution in $38 \mathrm{mT}$ Magnetic Field with Airflow $40 \mathrm{~m} / \mathrm{s}$ Velocity $(\mathrm{P}=1.5 \mathrm{kPa}$,

$$
\mathrm{U}=1.5 \mathrm{kV} \text { ) }
$$

As show in fig.8-10, in the airflow, electron dissipation not only includes the spread of the electrons and the compound of electrons and ions, but also includes the energy losses caused by electron movement in the airflow. So, discharge section gradually decreases with the increase of airflow. When the discharge power is certain, the section of discharge will shrink in order to reduce the electron losses caused by composition and diffusion and maintain the discharge. With the velocity of airflow rising, discharge will be unstable when it can't be maintained just relying on reducing the loss of composition and diffusion, as show in fig. 10 .

\section{The Discharge Evolution in Different Magnetic Field for Gas Conditions}

Using thin glass tube to inject butane into experimental section and observe the figure deformation of discharge section, in fig 11 , the pressure is $1.5 \mathrm{kpa}$ and the discharge voltage is $1.5 \mathrm{kv}$ with $38 \mathrm{mT}$ magnetic field. In non-flow condition, the butane can be ignited rapidly and the section of combustion is corresponding to the section of discharge. Generally, the figure of combustion is steady whereas the section of combustion changes sometime. 


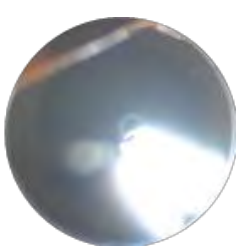

$0.6 \mathrm{~s}$

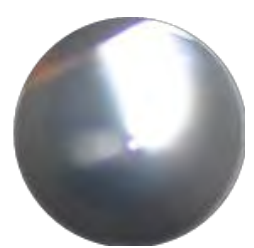

$1.3 \mathrm{~s}$

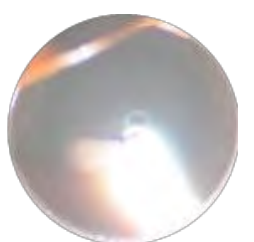

$2.3 \mathrm{~s}$

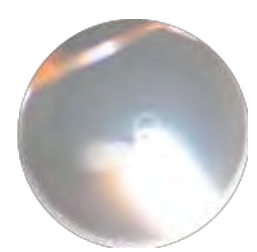

$3.5 \mathrm{~s}$

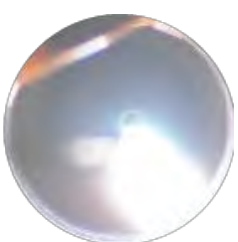

$4.6 \mathrm{~s}$

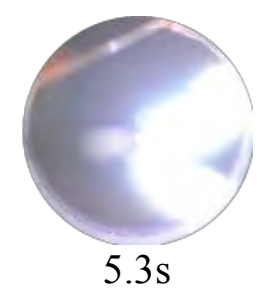

$5.3 \mathrm{~s}$

Fig. 11 The Discharge Evolution in Gas Flow with External Magnetic Field of $38 \mathrm{mT}(\mathrm{P}=1.5 \mathrm{kPa}$, $\mathrm{U}=1.5 \mathrm{kV})$

In fig 11 , the pressure is $1.5 \mathrm{kpa}$ and the discharge voltage is $1.5 \mathrm{kv}$ with $38 \mathrm{mT}$ magnetic field. in the condition of airflow $20 \mathrm{~m} / \mathrm{s}$ velocity, the butane can be ignited rapidly and mostly the section of combustion take place at the section of discharge, the figure and the position of combustion is comparatively fixed.

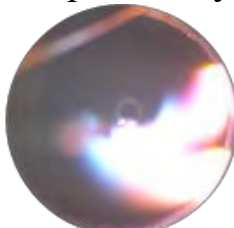

$0.6 \mathrm{~s}$

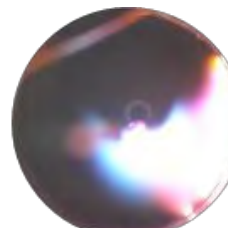

$1.3 \mathrm{~s}$

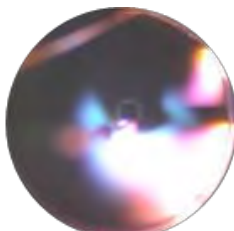

$2.5 \mathrm{~s}$

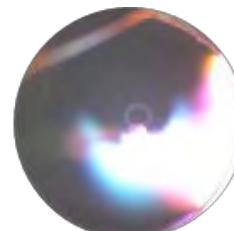

$3.3 \mathrm{~s}$

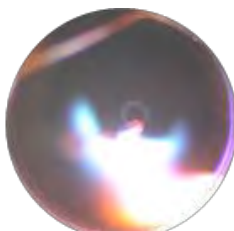

$4.1 \mathrm{~s}$

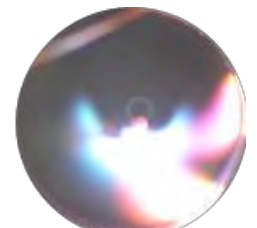

$5.3 \mathrm{~s}$

Fig. 12 Discharge Evolutions in Gas Flow and Airflow $20 \mathrm{~m} / \mathrm{s}$ Velocity with External Magnetic Field of $38 \mathrm{mT}(\mathrm{P}=1.5 \mathrm{kPa}, \mathrm{U}=1.5 \mathrm{kV})$

As shows in fig 11 and fig 12, the combustion can be ignited rapidly by the plasma generated by discharge no matter in flow condition or non-flow condition, nevertheless, the section of combustion mostly take place at the section of discharge and the combustion is steady. Obviously, on condition of using MHD assisted mixing and combustion, the cross section of combustion section becomes wider, which shows that on the effects of Lorentz force, the contacting surface between gas and air increase and the efficiency of combustion is improved.

\section{Conclusion}

The experimental system has been designed to study the idea of MHD-assisted mixing and combustion in non-premixed flows. Preliminary experiments on the study of the electrical discharge in the counter-flow jets of airflow and fuel (butane) and in the presence of magnetic field were carried out. The results show that the section of discharge appears regular motion and the contact surface has improved under the effect of MHD assisted mixing and combustion, in the end, the efficiency of combustion was increased.

\section{Acknowledgement}

This research was financially supported by the National Natural Science Foundation of China under Grants 51306207and 11372352 and Natural Science Foundation of Shaanxi province under Grants 2013JQ1016.

\section{References}

[1]Klimov A, Bityurin V, Grigorenko A, et al. Plasma Assisted Combustion of Heterogeneous Fuel in High-Speed Airflow[R]. AIAA 2009-1411, 2009.

[2]Bityurin V A, Bocharov A N, Advanced MHD Assisted Mixing of Reacting Streams[R]. AIAA $2001-0793,2001$.

[3]Bityurin V, Bocharov A, Klement'eva I, et al. Experimental and Numerical Study of MHD Assisted Mixing and Combustion[R]. AIAA 2006-1009, 2006. 
[4]Valentin A, Bityurin, Andrei V G. Evaluation of radiative heat transfer in combustion chamber of Al-H2O MHD generator[R]. AIAA 2012-0200, 2012.

[5]LI Yiwen, LI Yinghong, LU Haoyu, et al. Preliminary experimental investigation on MHD power generation using seeded supersonic argon flow as working fluid[J].Chinese Journal of Aeronautics, 24(12): 701-708, 2011. 